\title{
Curriculum Innovation in Industrial Engineering: Developing a New Degree Program
}

\section{Dr. Mary J. Meixell, Quinnipiac University}

Mary J. Meixell is an Associate Professor of Management and Industrial Engineering at Quinnipiac University in Hamden Connecticut, where she teaches courses in operations analysis and supply chain management. She earned a B.S. in Civil Engineering at Penn State University, an M.S. in Transportation at Massachusetts Institute of Technology, and a Ph.D. in Industrial Engineering at Lehigh University. Her areas of expertise are in production and logistics operations analysis and supply chain management. Dr. Meixell has extensive industry background in logistics management, production planning, supplier management and supply chain design in the automotive and telecommunications industries. Dr. Meixell's current research interests include sustainable supply chain management, performance implications of outsourcing, and curriculum development in undergraduate programs.

\section{Dr. Nebil Buyurgan, Quinnipiac University}

Nebil Buyurgan, Ph.D., is an Associate Professor in the Industrial Engineering Program at Quinnipiac University. Prior to joining QU, he served as Associate and Assistant Professor in the Industrial Engineering Department at the University of Arkansas. He received his doctorate in engineering management, from the University of Missouri-Rolla. As the author or coauthor of over 100 technical papers, his research interests include supply chain management, humanitarian and healthcare logistics, healthcare/medical informatics, and data standards. He has directed several projects funded by the National Science Foundation, Air Force Research Lab, and Wal-Mart Stores.

\section{Prof. Corey Kiassat, Quinnipiac University}

Dr. Corey Kiassat is an Assistant Professor of Industrial Engineering at Quinnipiac University and has a BASc and a PhD degree in Industrial Engineering from the University of Toronto. He has an MBA, majoring in Marketing and International Business, from York University. Corey is a Professional Engineer and has 11 years of industry experience in manufacturing engineering and operations management with General Motors in USA and Canada. He has also been involved with a start-up company in personalized preventive healthcare. Corey's research focus is on the role of people on performance of systems. His general research interests include process optimization, human reliability, distraction and human error, and failure risk analysis. 


\title{
Curriculum Innovation in Industrial Engineering: Developing a New Degree Program
}

\begin{abstract}
In this paper, we report on the development of a new industrial engineering program, framing it as a systems engineering process in the context of higher education curriculum development. The curriculum is described in detail, and innovative characteristics of the program are discussed. The resulting program is flexible, allowing the pursuit of accelerated graduate programs, a second major, various minor options, and study-abroad; relevant, tailored to the needs of industry partners in the vicinity; and practical, providing hands-on education, resulting in employment-ready graduates.
\end{abstract}

\section{Introduction}

Curriculum development and innovation is critical to successful programs in engineering. In this paper, we describe the development of a new industrial engineering (IE) program at a mediumsized private university in the northeast United States, Quinnipiac University. Small class sizes and high student-faculty interaction are among the distinguishing characteristics of the university. As such, IE is forecasted to have a total of approximately 80 students, or 20 per year. Currently, there are 19 IE students across the freshman, sophomore, and junior year. There is a healthy growth trend of four juniors, five sophomores, and 10 freshman students. The IE students are primarily from the region, with the majority being from CT, NY, MA, and NJ. The gender ratio is equal in the program and approximately $20 \%$ of the students are minority.

The development of this new IE program has been innovative as it is strategically designed to be well-balanced between engineering and other university programs, using the guidelines of NCEES fundamentals exam, as well the requirements for regional employment opportunities. The resulting program curriculum is thus both flexible and relevant. The flexibility allows the pursuit of a variety of minor degrees, study-abroad opportunities, as well as fast track bachelor's/master's degree programs, where a student can receive a bachelor's degree in IE and an MBA in less than the traditional 6 years. In addition, the curriculum is relevant as it is structured to allow for emphasis areas, aligned with regional employers' needs, maximizing employability in the student's preferred industry. In this paper, we describe the multi-year process followed for development of the new program using systems engineering process. In this view, the program is considered as the system that addresses the needs of identified stakeholders. Our program produces educated employment-ready students through a curriculum by which they are transformed into industrial engineers.

We draw from the scholarly education literature as an aid in framing the process from a comprehensive sociocultural viewpoint. From this perspective, context and influences are key drivers in the curriculum development process. Context can be viewed at the university level, and includes the mission of the university, the resources available, and the targeted size of the program. Influences may be internal within the program, and include expertise areas of the faculty and related engineering and other university programs that serve as opportunity areas for 
coordination. External influences certainly include accrediting bodies and licensing organizations; in this case, both ABET and NCEES helped to define the content of our IE program. An important influence, especially in building the student learner population, has been the challenge of working in a regional environment where there is little knowledge of the industrial engineering career path. The regional employer base also played and continues to influence program development, as both the IE core and the technical electives are structured to be responsive to employer needs. In the northeast US where Quinnipiac is located, the most common employers are hospital networks, financial and insurance companies, along with traditional manufacturers that range from small to large. Additionally, several principles were identified and used as an aid in curriculum decisions, including a smaller core, flexible technical electives for multiple emphasis areas, and broad based methodology courses.

In this paper, we first describe the development of the curriculum that integrates the principles of the system design process with curriculum development. The IE curriculum at Quinnipiac is then presented and discussed.

\section{A Curriculum Development Process}

Curriculum development can be an overwhelming undertaking when no previous program practice exists. In practice, colleges often look to their accrediting bodies, such as ABET for engineering programs, for guidance on curriculum, which requires external input from employers. Engineering programs ask their advisory board or council for input, and also rely on their internal panel of faculty experts, as well as exploring practice at peer university programs. Methodology-wise, industrial engineering faculty have used system theory ${ }^{[1]}$, domain analysis ${ }^{[2]}$ and structural models ${ }^{[3]}$ as an aid in curriculum development. Likewise, methods from the quality management and product development domain, specifically the House of Quality (HOQ) and Quality Function Deployment (QFD), have also been deployed in this particular context ${ }^{[4-8]}$.

The scholarly education literature on college curriculum is extensive, and includes numerous works that support curriculum development projects. A few notable research lines pertaining to higher education curriculum include Halliburton ${ }^{[9]}$, Dressel ${ }^{[10]}$, Conrad and Pratt ${ }^{[11]}$, Toombs and Tierney ${ }^{[12]}$, Diamond ${ }^{[13]}$ and others. Here, we refer to Lattuca and Stark's ${ }^{[14]}$ academic planning model as a framework within which to describe the components as well as the sociocultural context encompassing curriculum planning. Lattuca and Stark define academic plans broadly in terms of its elements, which include learners, purposes, content and sequence, instructional resources, instructional processes, assessment and evaluation. Importantly, these authors also define a process for developing curriculum at all levels, from an individual class meeting, to a course, to a major, to a university as a whole. The academic plan is continuously evaluated in this model, based on educational outcomes and then adjusted for improvement. Lattuca and Stark's curriculum development process is both descriptive and prescriptive, providing practitioners with a foundation for curriculum reform in a college setting and academics with a basis for future research in curriculum planning. As such, existing curricula can be described using their framework, and then improved through a prescriptive view through new issues that are identified and addressed in the course of evaluating and improving curricular programs.

An important concept in Lattuca and Stark's academic plan is the role of internal and external influences, both of which are important aspects of the sociocultural context in curriculum 
development in higher education in this particular context. The internal influences at the institution relate the college mission, resource limitations, and governance style to the curriculum, as well as influences at the unit level from faculty, the discipline, and student characteristics. The external influences include market forces, government, accrediting agencies, and disciplinary associations. Market forces include, but are not limited to, employer needs for skills, competencies and knowledge in the new hires, which are often prepared at a university, and via the curriculum.

In the case of this curriculum development project, the need to adhere to ABET requirements for curriculum was very clear. Perhaps not so clear was the usefulness of the NCEES Fundamental Exam content in making specific curricular decisions. Also, the college mission was a factor as it calls for a liberal education perspective to be linked to the university's pre-professional programs, and requires 46 credits of general education that must be accommodated in all university degree programs. Resource limitations needed to be considered in the development of this program in terms of classroom and laboratory development. Also, substantial faculty time has been needed for course development as several new courses are required each semester. Governance structure is also an important consideration, which has in part been addressed by initially housing the programs in the School of Business. As such, the governance structure was in place for developing and approving curriculum and other program related decisions.

3. Curriculum development using the systems engineering process

The process we followed to develop our new Industrial Engineering Program curriculum resembles the step-by-step systems engineering process ${ }^{[15]}$. The developed model for the systems engineering process is given in Figure 1.

\section{Identifying and Analyzing Program Stakeholders}

The development process started with identifying and analyzing program stakeholders. These were identified as the students, other programs at Quinnipiac, and industry partners in the vicinity. We analyzed the student profile including which geographic states they are coming from and their background (i.e. SAT, ACT scores) to understand what their expectations from the program might be and what our expectations from them should be. In addition, we also identified potential colleges and universities around the area as well as potential programs in our institution where we may receive transfer students from. In the same effort, we have also identified potential industries around the area and potential employer organizations who may hire the program graduates. We have also contacted a number of them to assess their employer needs and requirements. After these preliminary analyses stage, we have identified that we will receive students with interests in manufacturing, healthcare, supply chain management and financial engineering. We have also identified a number of companies in our region that can potentially provide internships, as well as provide full time employment after graduation for our students. Note that the Lattuca and Stark academic planning model addresses these program stakeholders as "influences" on the curriculum. Additional influences in this model that might be classified include government and faculty. 


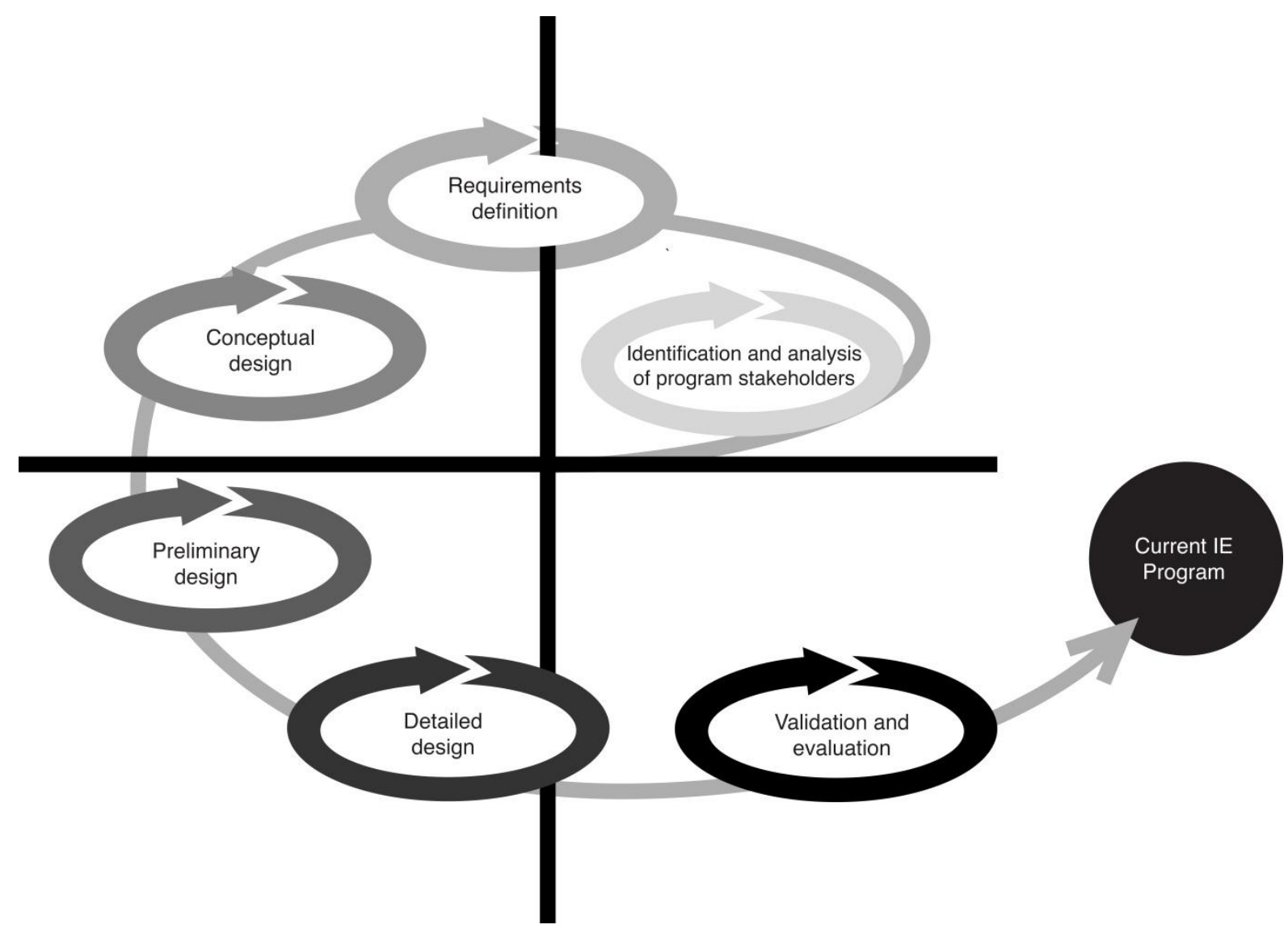

Figure 1. Systems Engineering Process.

\section{Requirements Definition}

The next step was to identify the program needs and requirements. We started with defining our strategic position in our institution and industrial engineering community. We wanted to provide several educational opportunities to our students while providing contemporary and relevant hands-on education. We also looked to provide our students with strong yet flexible industrial engineering background so that they will have different career opportunities. We analyzed some of the industrial engineering programs curricula in other institutions to identify innovative courses or other approaches that we can adopt. We have also considered other relevant programs in our institution to see if there would be opportunities to develop innovative and collaborative educational approaches.

Lattuca and Stark's academic planning model refer to these requirements as purposes and content. Additional considerations we took into account that are well reflected in the academic planning model are instructional resources and processes, both of which were important considerations in our program, especially considering the special issues associated with growing a new program where student enrollment is relatively low. For example, new program had to promote hands-on approaches in courses and outside the university to make it an active and dynamic learning experience. Lectures and in-class assignments had to be supported by laboratory exercises and term projects. 
While identifying requirements we had to consider the university's mission and vision, educational expectations and curriculum requirements. Since our program is designed as a leading educational program with high expectations and goals, we took ABET accreditation requirements as well as NCEES Fundamentals of Engineering exam requirements into consideration to develop our curriculum.

\section{Conceptual Design}

In the conceptual design phase, we focused on the need and requirements to develop and maintain such a successful program. We started with the faculty needs and the support for the faculty. How many faculty would we need to support the program and maintain the high quality of education? And, what expertise areas should be targeted? This was especially true when justifying our faculty requirements to administration, as well as looking for specific subdiscipline expertise, for future hirings. What would be the needs and requirements for the faculty including, teaching materials, classroom and other facility requirements, laboratories, library support, and time to develop the curriculum. We developed a number of alternative curricula. Most of them satisfied the previously identified needs and requirements.

\section{Preliminary Design}

In the preliminary design phase, we first identified evaluation criteria for our alternative curricula. We considered a number of constraints including number of faculty required, faculty teaching responsibilities, budgetary issues, course contents, number of required and elective courses, number of free elective courses, laboratory and equipment requirements etc. Then we evaluated the alternative curricula and evaluated some of them based on the criteria. We also conducted trade-off analyses to maximize opportunities for students who would pursue a second major, a minor or a graduate program. We also took the potential of study abroad opportunities for our students into consideration. Based on these analyses and considerations we developed a list of core industrial engineering courses as well as technical elective course. We also developed another list of mathematics and science courses to support industrial engineering courses which fulfill $\mathrm{ABET}$ accreditation requirements and the university course requirements. This iterative approach to curricular design may be inherent in Lattuca and Stark's model, but is an explicit feature of the systems engineering approach to curricular design.

\section{Detailed Design}

In the detailed design phase we finalized our curriculum and designed the prerequisite structure based on NCEES Fundamentals of Engineering (FE) exam requirements. NCEES publishes a reference handbook that essentially lists the topic areas and topics from which the exam questions are prepared. We mapped our identified courses with that list in two different ways. First, we mapped which courses will cover which topic areas. We tried to cover as many topic areas as possible with the required core Industrial Engineering courses. Then, we identified which topic areas will be required as prerequisite knowledge for courses. For example, we decided to include a quality control related course and an engineering statistics related course in the curriculum. We then decided that the quality control related course should cover most of the topics in the Quality topic area and engineering statistics related course should cover the topics in the Probability and Statistics topic area. These topic areas are both listed in the FE reference 
handbook. Then we decided that some of the topics in the Probability and Statistics should be required before some of the topics in Quality. This method provided us with a good prerequisite structure. We then mapped the courses to appropriate semesters. We considered the offerings of supporting courses and faculty teaching responsibilities per semester and made a few minor changes to our curriculum. Lattuca and Stark's model also calls out sequencing of topics as an essential element in curricular design.

Great emphasis is placed on a practical and hands-on education, in synch with industry needs in the area. The purpose is to have employment-ready students upon graduation. A market analysis by the faculty, including consultation with industry partners, has resulted in the appropriate emphasis areas and technical electives. Many courses are designed with a final project element where students perform on-site visits and recommend solutions for observed problems. The mandatory internship component of the curriculum has also benefitted the students and enthusiastically received by the industry partners, once again leading to employment-ready graduates. This prepares them to a Senior Design course sequence that draws on all prior courses by exposing the students to an integrated, capstone design experience.

\section{Validation and Evaluation}

In order to validate the curriculum we consulted the program advisory board which consists of practicing professionals in manufacturing, healthcare, supply chain management and financial engineering as well as academicians. The curriculum is also evaluated and approved by the college undergraduate curriculum committee as well as the university senate to make sure it complies with the university and state requirements, as state approval of the IE program had been acquired before faculty were hired and so needed to be included as a constraint on the ongoing development of the curriculum. This is recognized in the Lattuca and Stark model through the influence of the government stakeholder.

At the next development stage we identified courses where we intend to conduct program evaluation and continuous improvement, as promoted and expected in the accreditation process. This is consistent with the Lattuca and Stark academic planning model which calls for ongoing assessment and evaluation at all levels of the curriculum: program, course, and individual class.

\section{A New Industrial Engineering Curriculum}

The IE curriculum developed with all the aforementioned objectives, features, criteria and constraints is displayed in Figure 2. Note that the program comprises 120 credits, the minimum number of credits for a BSIE. There are ten required industrial engineering courses and the students start taking these courses in semester three of the program in order to introduce them to IE as early as possible. In addition, students have to take five technical elective courses four of which must be industrial engineering courses. The fifth technical elective course can be any junior level engineering course from other engineering programs as well as industrial engineering. Students also take a total of 30 credits of Mathematics and Science courses. Three credits of these courses are electives and can be taken from a list of preapproved courses. In addition, the curriculum also includes six credits of open elective courses. This flexibility, along with the minimal requirement of 120 credits, provides students with a great opportunity to pursue a second major, such as Software Engineering, a minor, such as Management, or an accelerated 
graduate study, such as the MBA. Students can choose certain courses as electives that count towards their second major or minor.

Study-abroad opportunity was another consideration. We did not assign required core courses in the spring semester of junior year to allow student to pursue a study-abroad. If studying abroad, IE students take their technical elective courses in their last two semesters of study. Note that our program requires an internship. We included a seminar course in our curriculum before their internship where resume writing, interview skills and ethical issues are covered.

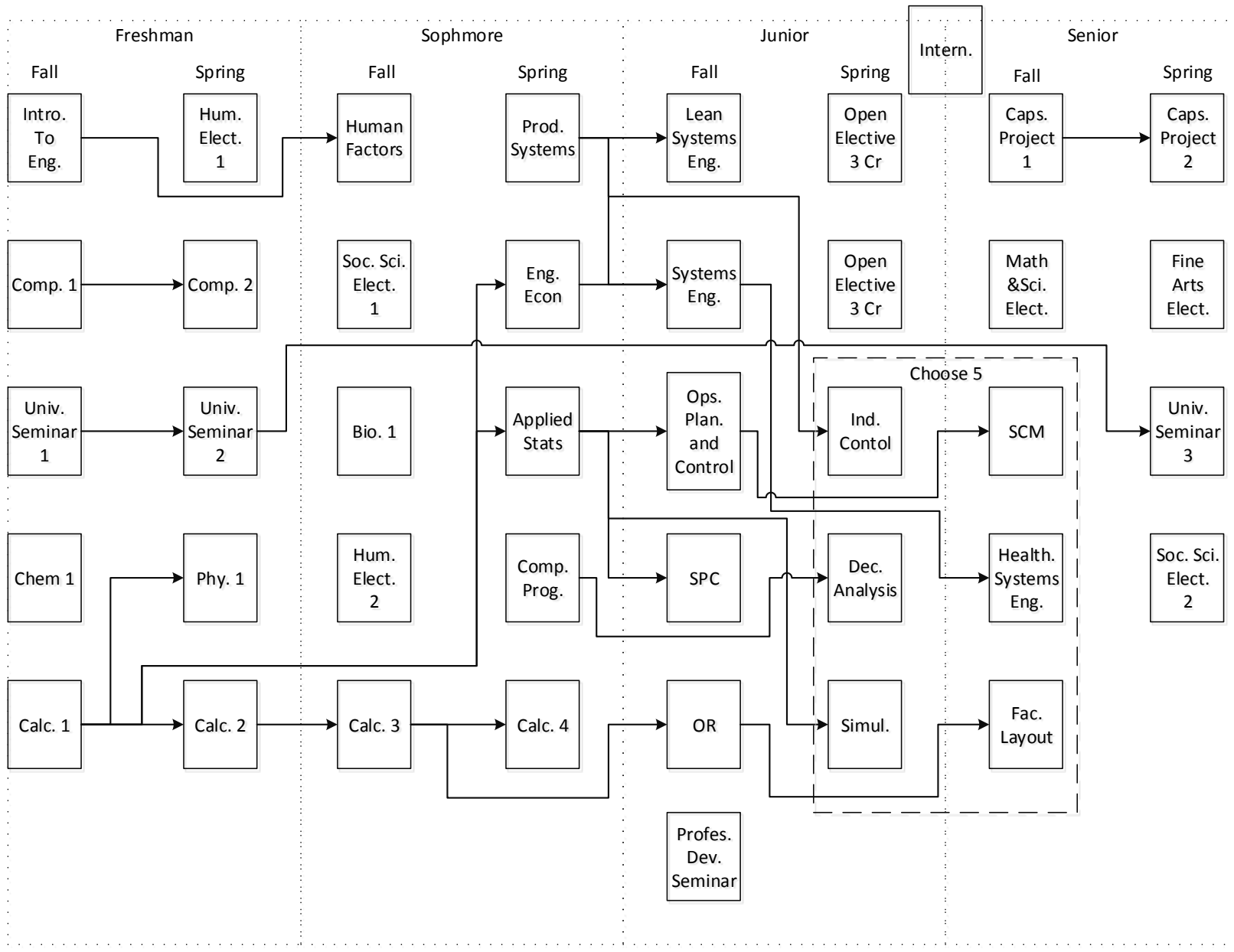

Figure 2. Industrial Engineering Curriculum.

We also considered the course load per semester and did not exceed 16 credit hours in first five semesters. This ensures the students do not pay a premium towards their tuition fees. Last three semesters can vary between 12 and 15 credit hours depending on elective course selection. This also provides students flexibility and opportunities to pursue other educational options. All of our current upper level students either pursue a minor, dedicate a semester for study abroad, or an accelerated master's program in which they start taking graduate level courses in their last semester. 


\section{Summary and Conclusions}

A new engineering school is the latest addition at a growing, medium-sized, private university in northeastern United States. Industrial Engineering is one of four new engineering programs, along with Mechanical, Civil and Software Engineering. In this paper, we have described the process that has led to a program considered to be innovative, relevant, practical, and flexible. A systems engineering process has been followed by the faculty designing the curriculum to first identify and analyze the stakeholders, then define the requirements, before proceeding to conceptual design, preliminary design, and detailed design. The process is completed by validation and evaluation, using external resources, in the form of an advisory board, and internal resources, in the form of the various university bodies. In this paper, we further inform the use of systems engineering design with a curriculum development approach from the scholarly education literature, which calls for explicit consideration of eight essential elements: learners, purposes, content and sequence, instructional resources, instructional processes, assessment and evaluation. Additionally, numerous internal and external sociocultural influences are important to academic planning in this context. These can each be readily related to the systems engineering approach, as demonstrated in this paper.

The IE curriculum satisfies all ABET requirements as well as those of the NCEES FE exam. In addition, the curriculum presents many academic choices to the students, including the pursuit of a double major, a minor, and accelerated master's programs. Furthermore, the opportunity for a study-abroad term is built into the curriculum where a student can study abroad in semester six of the program and not fall behind in any way.

As we proceed towards graduating our first cohort and applying for ABET accreditation, we are working towards several other opportunities in the near future. As an immediate future work, we plan to experiment with offering flexible credit hour courses. Existing IE courses can be offered as a combination of one- or two-credit courses, providing the opportunity to non-IE students to only take special topics that appeal to them. In addition, we are considering more emphasis areas to satisfy market needs and make the IE program more attractive to potential students. We are also contemplating two graduate programs with courses that could also be taken as technical electives by senior undergraduate IE students.

Lastly, the next steps of development of the industrial engineering program will include an increased focus on general education studies. Our university has undertaken a revision of its general education curriculum with the intent to more closely tie studies in the humanities and social sciences with those in the degree programs, including industrial engineering. This reciprocity between general education and engineering programs holds great promise for improved educational outcomes. 


\section{Bibliography}

[1] Z. Deng, "Curriculum Planning and Systems Change," in International Encyclopedia of Education (Third Edition), B. McGaw, E. Baker, and P. Penelope, Eds. Oxford: Elsevier, 2010, pp. 384-389.

[2] H. D. White, "Computing a curriculum: descriptor-based domain analysis for educators," Information Processing \& Management, vol. 37, pp. 91-117, 2001.

[3] C. M. Bunăiaşu and A.-C. Strungă, "A Potential Methodological Tool in Order to Plan the Curriculum in School," Procedia - Social and Behavioral Sciences, vol. 76, pp. 140-145, 2013.

[4] M. E. Gonzalez, G. Quesada, J. Mueller, and R. D. Mueller, "International business curriculum design: identifying the voice of the customer using QFD," Journal of International Education in Business, vol. 4, pp. 6-29, 2011.

[5] A. Aytac and V. Deniz, "Quality Function Deployment in Education: A Curriculum Review," Quality and Quantity, vol. 39, pp. 507-514, 082005.

[6] J. W. Denton, V. Franke, and K. N. Surendra, "Curriculum and Course Design: A New Approach Using Quality Function Deployment," Journal of Education for Business, vol. 81, pp. 111-117, 11/01 2013/10/03 2005.

[7] A. Crişan and R. Enache, "Designing customer oriented courses and curricula in higher education. A possible model," Procedia - Social and Behavioral Sciences, vol. 11, pp. 235-239, 2011.

[8] J. S. Pérez and F. G. Aleu, "Industrial Engineering Approach to Develop an Industrial Engineering Curriculum," IIE Annual Conference. Proceedings, pp. 271-277, 2009.

[9] D. Halliburton, "Designing curriculum," in Developing the college curriculum, A. W. Chickering, D. Halliburton, W. H. Berquist, and J. Lindquist, Eds. Washington, DC: Councile for the Advancement of Small colleges, 1977, pp. 51-74.

[10] P. L. Dressel, Improving degree programs: A guide to curriculum development, administration and review. San Francisco: Jossey-Boss, 1980.

[11] C. Conrad and A. M. Pratt, "Making decisions about the curriculum: from metaphor to model," The Journal of Higher Education, vol. 54, pp. 16-30, 1983.

[12] W. Toombs and W. G. Tierney, "Curriculum definitions and reference points," Journal of Curriculum and Supervision, vol. 8, pp. 175-195, 1993.

[13] R. M. Diamond, Designing and assessing courses and curricula: A practical guide, 3rd ed. San Francisco: Jossey-Boss, 2008.

[14] L. R. Lattuca and J. S. Stark, Shaping the college curriculum: Academic plans in context. San Francisco, CA: Jossey-Bass, 2009.

[15] B. S. Blanchard and W. J. Fabrycky, Systems Engineering and Analysis, 5th ed. Upper Saddle River, NJ: Prentice Hall International Series in Industrial \& Systems Engineering, 2010. 